\title{
Total debranching hybrid total arch replacement with a novel frozen elephant trunk for acute aortic dissection type A
}

Hiroyuki Kamiya, MD, PhD, Sentaro Nakanishi, MD, Hayato Ise, MD, and Hiroto Kitahara, MD, Asahikawa, Japan

\author{
From the Department of Cardiac Surgery, Asahikawa Medical University, Asahikawa, Hokkaido, Japan. \\ Disclosures: Authors have nothing to disclose with regard to commercial support. \\ No funding was provided for this article. \\ Received for publication Jan 12, 2019; revisions received March 14, 2019; accepted for publication June 4, 2019 ; \\ available ahead of print Aug 27, 2019. \\ Address for reprints: Hiroyuki Kamiya, MD, PhD, Department of Cardiac Surgery, Asahikawa Medical Univer- \\ sity, Midorigaoka Higashi 2-1-1-1, Asahikawa 078-8510, Japan (E-mail: kamiya@asahikawa-med.ac.jp). \\ J Thorac Cardiovasc Surg 2020;159:e1-4 \\ $0022-5223$ \\ Copyright (C) 2019 by The American Association for Thoracic Surgery. Published by Elsevier Inc. This is an open \\ access article under the CC BY-NC-ND license (http://creativecommons.org/licenses/by-nc-nd/4.0/). \\ https://doi.org/10.1016/j.jtcvs.2019.06.064
}

Total arch replacement is an ideal surgical procedure for acute aortic type A dissection for preventing adverse events in the downstream aortic segments during later follow-up. ${ }^{1-3}$ The procedure is occasionally challenging, however, because of the very fragile aortic wall in addition to the deep surgical field. Moreover, dissection often compromises supra-aortic vessels, and ensuring perfusion in the true lumen of the supra-aortic vessels is therefore sometimes difficult during total arch replacement. To simplify the procedure and ensure complete true-lumen perfusion in all supra-aortic vessels during total arch replacement, we used a total debranching method (Video 1), as applied in thoracic endovascular aortic repair. $^{4}$

\section{PREINCISION PREPARATION}

A central venous catheter is inserted from the femoral vein. Disinfection and surgical draping are applied in the area of bilateral carotid and axillary arteries.

\section{STEP 1: ENSURING PERFUSION OF THE BRAIN AND UPPER BODY}

First, 3 small incisions are made to expose the right and left common carotid arteries and the left axillary

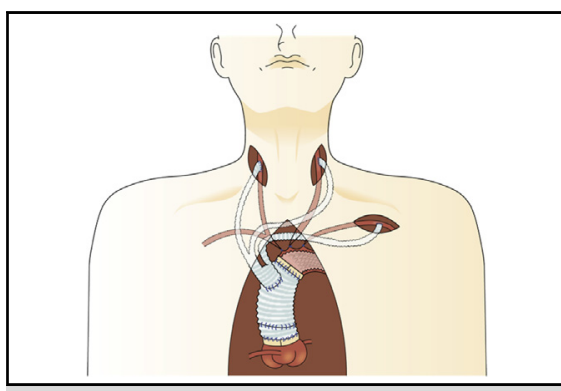

Total debranching hybrid total arch replacement with novel frozen elephant trunk.

\section{Central Message}

Total debranching of the supra-aortic vessels with a novel frozen elephant trunk technique facilitated total arch replacement, ensuring optimal brain protection in acute aortic dissection type A.

See Commentary on page e5.

artery. Median sternotomy is performed. A body of a quadrifurcated graft (Intergard, Getinge, Germany) is positioned at the level of the ascending aorta, and the 3 branches are pulled to the 3 small skin incisions. The grafts are tunneled not directly along the common carotid arteries, but rather in the layer just below the sternum to avoid recurrent laryngeal nerve injury. After systemic

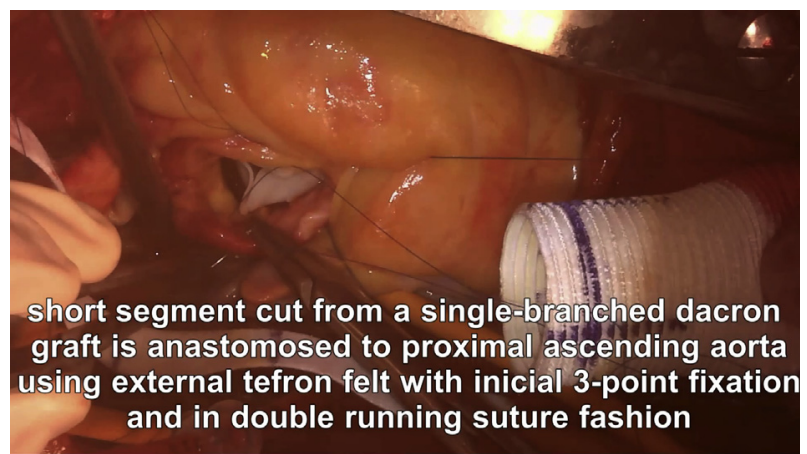

VIDEO 1. Total debranching hybrid total arch replacement with novel frozen elephant trunk. $C T$, Computed tomography; 3DCT, 3-dimensional computed tomography. Video available at: https://www.jtcvs.org/article/ S0022-5223(19)31363-7/fulltext. 
(1)
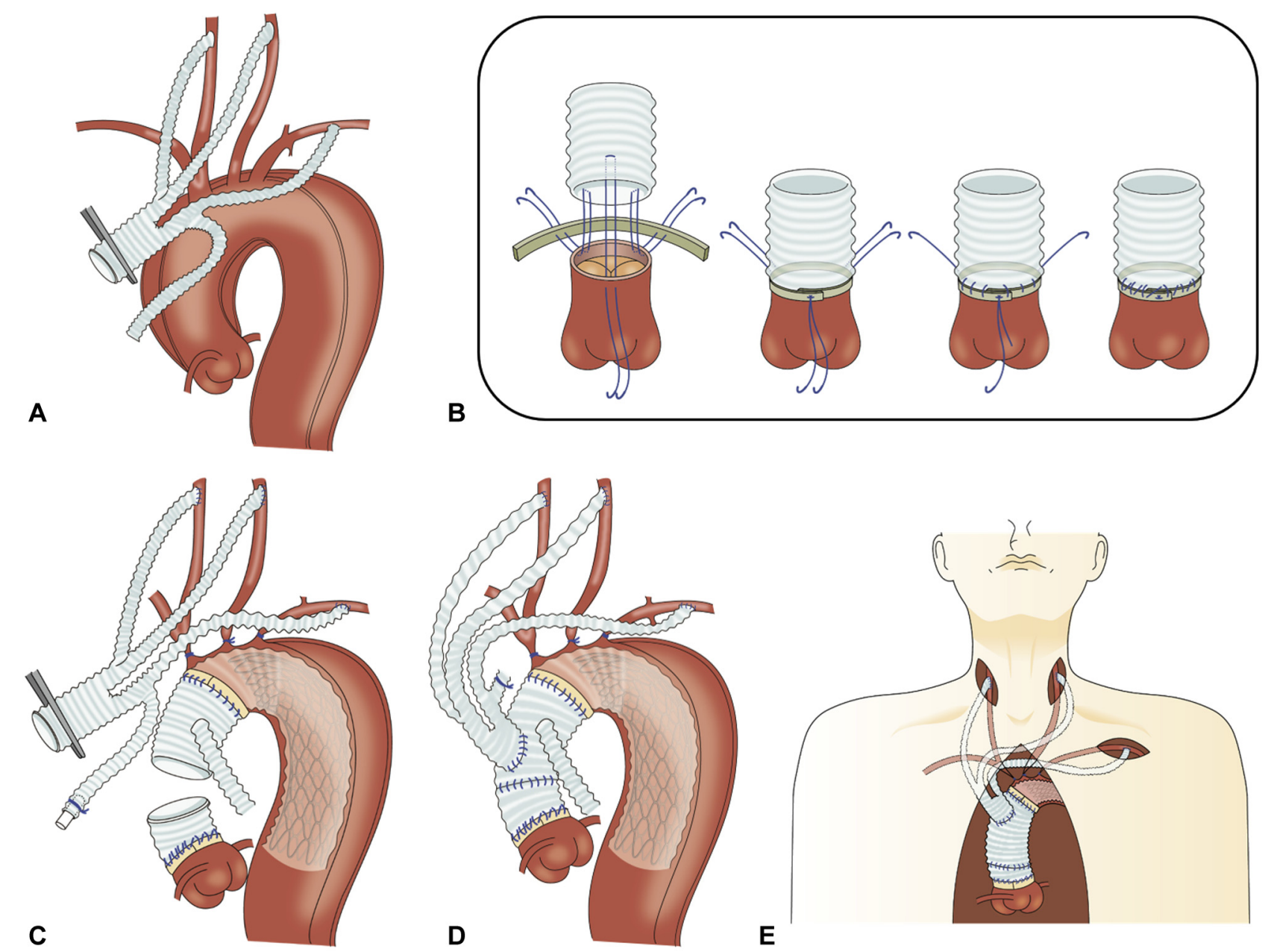

FIGURE 1. Schema of total arch replacement with total debranching of the supra-aortic vessels by using a quadrifurcated graft and a novel frozen elephant trunk technique for acute aortic type A dissection. A, After median sternotomy, 3 branches of quadrifurcated graft are tunneled to 3 small skin incisions and anastomosed one by one to the right carotid, left carotid, and left axillary arteries. Cardiopulmonary bypass is started through the fourth branch of the quadrifurcated graft. B, The ascending aorta is transected at a level $1 \mathrm{~cm}$ distal to the sinotubular junction. A short segment of a single-branched graft is anastomosed to the proximal ascending aorta with external polytetrafluoroethylene felt enforcement, with initial 3-point fixation and then in double running suture fashion. C, After ligation of all 3 native supra-aortic vessels, moderate hypothermic circulatory arrest with selective cerebral perfusion is initiated. The ascending aorta is transected at the level $2 \mathrm{~cm}$ proximal to the brachiocephalic trunk, and a frozen elephant trunk device is inserted into the aortic arch. A single-branched graft is anastomosed to the residual native distal ascending aorta together with the frozen elephant trunk. D, The main body of the quadrifurcated graft is anastomosed to the single-branched graft in end-to-side fashion. E, End-to-side anastomosis of the quadrifurcated graft with the singlebranched graft is performed, followed by end-to-end anastomosis of the proximal short graft with the distal graft. F, Final schema of the procedure.

heparinization, the right common carotid, left common carotid, and left axillary arteries are anastomosed one by one with branches of the graft (Figure 1,A). After finishing all 3 anastomoses, cardiopulmonary bypass (CPB) is started with 4.5 to $5.0 \mathrm{~L} / \mathrm{min}$ flow (cardiac index, 2.4) through the fourth branch of the quadrifurcated graft and bicaval venous drainage.

\section{STEP 2: CARDIOPROTECTION AND SURGICAL MANAGEMENT OF THE AORTIC ROOT}

The left atrium is vented through the right upper pulmonary vein. The ascending aorta is crossclamped, and retrograde cardioplegia is applied under control of perfusion pressure. The ascending aorta is transected at $1 \mathrm{~cm}$ distal to the sinotubular junction. The dissected intima is fixed with BioGlue (CryoLife International Inc, Kennesaw, Ga) as necessary. A short segment cut from a singlebranched Dacron polyester fabric graft (J-Graft; Japan Lifeline, Tokyo, Japan) is anastomosed to the proximal ascending aorta with external polytetrafluoroethylene felt enforcement, with initial 3-point fixation and then in double running suture fashion (Figure 1, B). All lines of anastomosis are sealed with the BioGlue. If needed, root replacement is performed in this phase. 

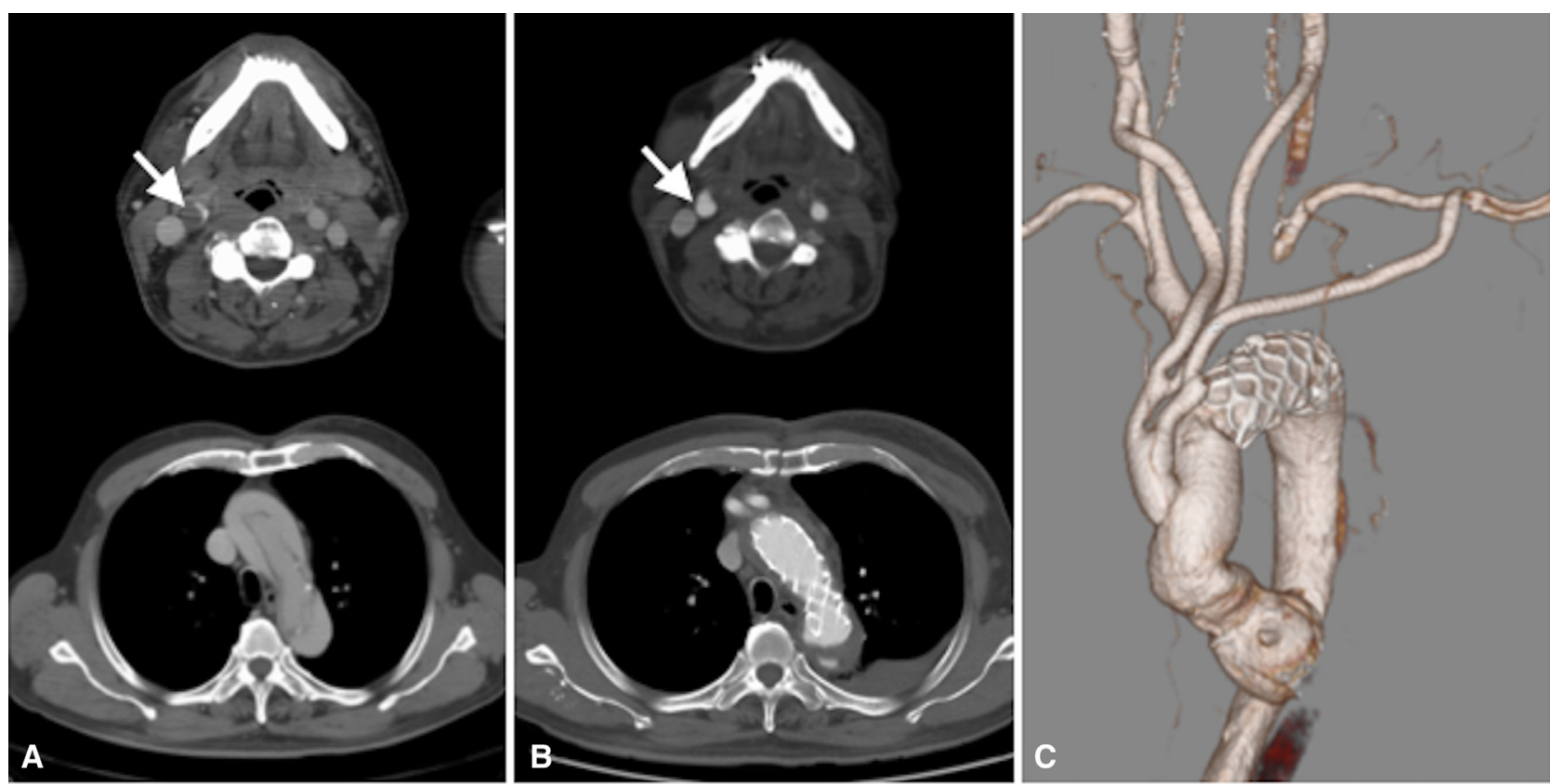

FIGURE 2. A, Preoperative computed tomography showing arch dissection extending to the right common carotid artery (white arrow). B, Postoperative computed tomography showing a patent true lumen in the right common carotid artery (white arrow). C, Postoperative computed tomographic 3-dimensional reconstructed model.

\section{STEP 3: HYBRID REPLACEMENT OF THE AORTIC ARCH}

When rectal temperature reaches $28^{\circ} \mathrm{C}$, CPB flow is reduced to $2.0 \mathrm{~L} / \mathrm{min}$ and all 3 native supra-aortic vessels are ligated, thereby inducing moderate hypothermic circulatory arrest with selective cerebral perfusion. The ascending aorta is transected at $2 \mathrm{~cm}$ proximal to the brachiocephalic trunk. Regardless of the position of the intimal tear, a very soft frozen elephant trunk device (Frozenix; Japan Lifeline) is inserted into the aortic arch. The size of the frozen elephant trunk is determined by preoperative computed tomography but typically ranges from 27 to $31 \mathrm{~mm}$ in diameter and $90 \mathrm{~mm}$ in length, because an overly long prosthesis increases the risk of paraplegia.

A single-branched Dacron polyester fabric graft is anastomosed to the residual native distal ascending aorta together with the frozen elephant trunk with a technique similar to that used for the proximal anastomosis (Figure $1, C)$. Thereafter, the main body of quadrifurcated graft is anastomosed to the single-branched graft in end-to-side fashion (Figure 1,D). The arterial perfusion line is switched from the fourth branch of the quadrifurcated graft to the side branch of the distal ascending graft.

\section{STEP 4: FINALIZATION OF AORTIC CONTINUITY} AND END OF EXTRACORPOREAL CIRCULATION

The proximal and distal grafts are anastomosed in end-toend fashion (Figure 1,D). The aorta is declamped, and active deairing through the fourth branch of the quadrifurcated graft, weaning from $\mathrm{CPB}$, and closure are achieved according to standard techniques (Figure 1,E).

\section{RESULTS}

From November 2017 to December 2018, 7 patients underwent the procedure. Mean operative, CPB, and selective cerebral perfusion times were $443.1 \pm 123.8,152.7 \pm 57.0$, and $34.9 \pm 10.4 \mathrm{~min}$, respectively. No patient showed postoperative neurologic symptoms. The false lumens of the right common carotid artery that had previously been seen in 4 patients had completely disappeared in postoperative computed tomography (Figure 2). Median length of hospital stay was 19 days. There was a single 30-day death of acute hepatitis.

\section{DISCUSSION}

The procedure might offer a good therapeutic option for acute aortic type A dissection, ensuring optimal brain protection and minimizing the risks, particularly for patients who have preoperative brain malperfusion. Moreover, frozen elephant trunk would be an ideal landing zone for potential thoracic endovascular aortic repair for late-phase aortic events.

\section{References}

1. Inoue Y, Matsuda H, Omura A, Seike Y, Uehara K, Sasaki H, et al. What is the optimal surgical strategy for Stanford type A acute aortic dissection in patients with a patent false lumen at the descending aorta? Eur J Cardiothorac Surg. 2018;54:933-9. 
2. Poon SS, Theologou T, Harrington D, Kuduvalli M, Oo A, Field M. Hemiarch versus total aortic arch replacement in acute type A dissection: a systematic review and meta-analysis. Ann Cardiothorac Surg. 2016;5:156-73.

3. Rylski B, Beyersdorf F, Kari FA, Schlosser J, Blanke P, Siepe M. Acute type A aortic dissection extending beyond ascending aorta: limited or exten- sive distal repair. J Thorac Cardiovasc Surg. 2014;148:949-54; discussion 954.

4. Kobayashi K1, Ohata T, Ueda H, Kurimoto Y. Early outcomes of extra-thoracic debranching thoracic endovascular aortic repair for distal aortic arch disease. J Artif Organs. 2014;17:236-42. 